\title{
The efficiency analysis of different combined cycle power plants based on the impact of selected parameters
}

\author{
Tien-Dat Hoang ${ }^{\mathrm{a}}$, Daniel Kazimierz Pawluskiewicz ${ }^{\mathrm{b}}$ \\ ${ }^{a}$ Tien-Dat Hoang, Thai Nguyen University of Technology, Thai Nguyen 250000, Vietnam \\ ${ }^{b}$ Daniel Kazimierz Pawluskiewicz, AGH University of Science and Technology, Kraków 30-059, Poland
}

\begin{abstract}
The reasons why combined cycles are more and more popular and being taken under consideration as one of the main types of power plants are quite varied. The main reason is efficiency. Nowadays, combined cycle power plants can achieve more than $60 \%$ efficiency what makes them one of the most efficient. It is important due to limitation of fossil fuels resources as well as environmental protection. Such constrictions are able to decrease $\mathrm{CO}_{2}, \mathrm{SO}_{2}, \mathrm{NO}_{\mathrm{X}}$ and dust production. That makes them suitable for a policy of decreasing global warming which affects people all around the world. The operation of combined cycle power plant is affected by many factors which are not only related with construction of a system but also ambient conditions. In present study, three different combined cycles were modeled in the Gate Cycle software: single-pressure with supplementary firing, dual-pressure and triple-pressure reheat cycle. Ambient temperature, pressure ratio in the gas part and temperature at the inlet to the gas turbine were investigated as the most significant factors which affect efficiency and power production in whole system.
\end{abstract}

Keywords: Combined-cycle power plant, electric power generation, efficiency, power output

\section{Introduction}

Combined cycle is defined as one system composed of two thermal cycles. In such system efficiency of both parts is higher than when they work separately [1]. The trend is to achieve the highest possible inlet temperature to the gas turbine and temperature of outlet gases is the lowest so system losses are reduced. The most popular system is a system combined of two cycles- gas cycle (Brayton cycle) which works on higher temperatures and steam cycle (Rankine cycle) which works on lower temperatures. Hot exhaust gases from Brayton cycle are used to produce hot high-pressure steam in Rankine cycle with a use of Heat Recovery Steam Generator (HRSG) [2], [3]. This combination is a result of application advantages and elimination disadvantages of both cycles to receive growth in efficiency [4], [5]. The advantage of Brayton cycle is very high temperature of working medium ranging from 700 to $1650 \mathrm{~K}$ while disadvantage is high temperature of exhaust gases [6]. However, Rankine part is characterized by lower operational temperatures but with problematic process of heat exchange which requires huge surface and causes extra costs [4].

Currently, there are a lot of different types of combined cycles which are built as new objects or as a modernization of the old ones. The most popular and efficient types are dual- or triple-pressure cycles. As it is shown in [7] the optimum gas turbine cycle should be a reheat cycle because not only higher exhaust gas temperature but also lower wetness of medium (even $5 \%$ percentage point decrease). In order to obtain the highest possible efficiencies of them, it is important to optimize their performances and operating parameters. Especially, by increasing the turbine inlet temperature in Brayton cycle which can be achieved by increasing combustion temperature or by applying different technologies of turbine's cooling system [8]. However, as it was shown in [9], it is possible to reach overall combined cycle

Manuscript received October 25, 2015; revised April 5, 2016.

Corresponding author. Tel.: +84 987344 991; E-mail address: hoangdat@ tnut.edu.vn.

doi: 10.12720/sgce.5.2.77-85 
efficiencies on existing plants only by optimizing HRSG. Because most of manufacturers design their gas turbines for ISO ambient conditions (temperature $15^{\circ} \mathrm{C}$, pressure 1.013 bar and $60 \%$ relative humidity) combined cycles are sensitive on change of these conditions [10]. Due to that impact of these parameters need to be examined how efficiency and power production is changed according to ambient temperature, pressure and relative humidity [11], [12].

Nomenclature

\begin{tabular}{|c|c|}
\hline $\mathrm{C}$ & Compressor \\
\hline $\mathrm{CC}$ & Combined cycle \\
\hline CMB & Combustion chamber \\
\hline CND & Of the condensator \\
\hline CONDEN & Condensator \\
\hline DB & Duct burners \\
\hline ECON & Economizer \\
\hline EVAP & Evaporator \\
\hline EX & Turbine in GS \\
\hline GAS1/2 & Air/natural gas \\
\hline GT & Gas turbine \\
\hline HP & High pressure \\
\hline HRSG & Heat recovery steam generator \\
\hline IP & Intermediate pressure \\
\hline LP & Low pressure \\
\hline MIX & Mixer \\
\hline PP & Power plant \\
\hline ST & Steam turbine \\
\hline SF & Supplementary firing \\
\hline SPHT & Super heater \\
\hline TMX & $\mathrm{T}$ mixer \\
\hline WHTR & Water heater \\
\hline 1P & Single-pressure \\
\hline $2 \mathrm{P}$ & Dual-pressure \\
\hline 3PR & Triple-pressure with reheat \\
\hline el & Refer to electric \\
\hline$\beta_{\mathrm{K}}$ & Pressure ratio \\
\hline$\eta_{\mathrm{el}}$ & Efficiency \\
\hline $\mathrm{K}$ & Kelvin \\
\hline $\mathrm{N}_{\mathrm{el}}$ & Net power \\
\hline $\mathrm{T}$ & Temperature \\
\hline $\mathrm{T}_{3 \mathrm{a}}$ & Gas turbine inlet temperature \\
\hline $\mathrm{T}_{1 \mathrm{a}}$ & Ambient temperature \\
\hline
\end{tabular}

The results were obtained in thermodynamic simulation created in Gate Cycle ${ }^{\mathrm{TM}}$ software (Table 1). That software serves as a tool to project power plant cycles. One of its abilities is to model and analyze combined cycle. Based on its functions, it is possible to analyze and predict effects of ambient conditions change, fuel type, settings of turbine blades or change in combustion temperature. Thanks to that, during design process feasible is to compute and check if projected model is correct what can help to prevent errors and big losses in the future.

\section{Assumptions}

The analysis was based on three different CC models: 
- Single-pressure with supplementary firing

- Dual-pressure

- Triple-pressure reheat cycle

The single-pressure CC with supplementary firing has got installed duck burners which are a way of increasing the PP output. Supplementary firing in HRSG can be applied because usually there is enough oxygen in the exhaust gas to be used in combustion [10]. Although that operation increases the exhaust gas temperature it can decrease efficiency of whole system. That technology can reduce power generation drop caused by a rise in the ambient temperature. However, its properties make such construction suitable only for special applications where it is economically reasonable [13]. Especially for cogeneration of heat and power, it can be applied where both electrical and thermal outputs are crucial for PP operation [14].

Table 1. Selected data for the Gate Cycle simulation of the combined cycle power plant at the design point (for selected turbine's inlet temperature)

\begin{tabular}{lllll}
\hline Parameter & unit & $1 \mathrm{P}$ & $2 \mathrm{P}$ & $3 \mathrm{PR}$ \\
\hline Air mass flow rate & $\mathrm{kg} / \mathrm{s}$ & 400 & 415 & 420 \\
Natural gas, LHV & $\mathrm{kJ} / \mathrm{kg}$ & 50044 & 50044 & 50044 \\
Gas inlet temperature & $\mathrm{K}$ & 293.5 & 298.5 & $298.5 \mathrm{~K}$ \\
Compressor efficiency & & 0.9 & 0.9 & 0.9 \\
Combustion efficiency & & 0.995 & 0.995 & 0.995 \\
Turbine's efficiency & & 0.9 & 0.9 & 0.9 \\
Generator efficiency & & 0.99 & 0.99 & 0.99 \\
Turbine's inlet temperature & $\mathrm{K}$ & 1200 & 1500 & 1400 \\
Turbine's outlet temperature & $\mathrm{K}$ & 861.46 & 884.52 & 817.99 \\
Duct pressure drop & $\mathrm{kPa}$ & 3.78 & 3.74 & 3.74 \\
Condenser's operating pressure & $\mathrm{kPa}$ & 5.03 & 5.03 & 5.06 \\
HP/IP/LP superheater's efficiency & & 0.85 & $0.82 / 0.8$ & $0.95 / 0.94 / 0.8$ \\
HP/IP/LP turbine's efficiency & & 0.9 & $0.9 /-/ 0.86$ & $0.9 / 0.9 / 0.86$ \\
HP/IP economizer's efficiency & & 0.85 & 0.85 & $0.85 / 0.8$ \\
HP/ IP/LP evaporator's efficiency & & 0.92 & $0.94 / 0.9$ & $0.89 / 0.89 / 0.86$ \\
Condenser's operating pressure & $\mathrm{kPa}$ & 5.03 & 5.03 & 5.06 \\
Pump efficiency & & 0.85 & 0.8 & 0.8 \\
Condenser's operating pressure & $\mathrm{kPa}$ & 5.03 & 5.03 & 5.06 \\
GT generator losses & $\mathrm{kW}$ & 907.7668 & 1738.72 & 1509.089 \\
Net cycle LHV heat rate & $\mathrm{kJ} / \mathrm{kW}-\mathrm{sec}$ & 2.4598 & 1.82 & 1.8123 \\
\hline
\end{tabular}

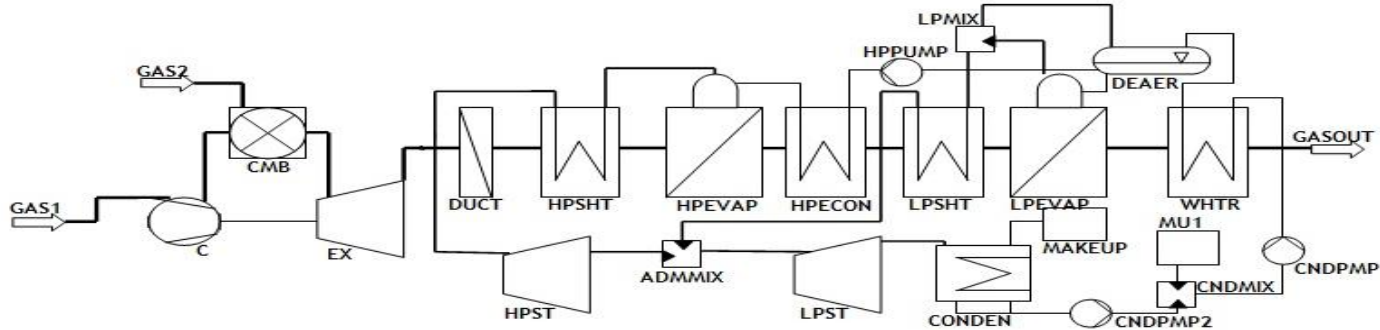

Fig. 1. Single pressure combined cycle with supplementary firing power plant.

In the single pressure $\mathrm{CC}$ shown on Fig. 1, GAS1 is compressed in $\mathrm{C}$ and then transported to $\mathrm{CMB}$ where takes part in combustion of GAS2. Exhaust gas is then expanded in EX and through DUCT delivered to DB where supplementary firing uses rest of oxygen and increase temperature of the gas. Then the gas is transported through HRSG which is built from economizer, evaporator and superheater. 
In the economizer the feed water achieve temperature close to its saturation point. In the evaporator, the medium is evaporated at constant temperature and pressure. The superheater superheats previously separated stream. Steam which is already expanded in three-stage ST is pumped by PUMP1 to M1 where is mixed with process water tank MU1 and return condensate MU2. PUMP2 pumps water to deaerator from which is delivered to EVAP2 to be heated up. Then by PUMP3 is split into temperature controller and economizer where is heated up again [10], [15].

In dual-pressure (Fig. 2) and triple-pressure with reheat (Fig. 3) CC energy use in HRSG is increased by adding additional pressure stages. In these cycles high pressure steam come back to HRSG after expansion in HPST. There it is mixed with steam from intermediate pressure preheater. After that steam is heated up to the temperature almost equal to the high pressure steam.

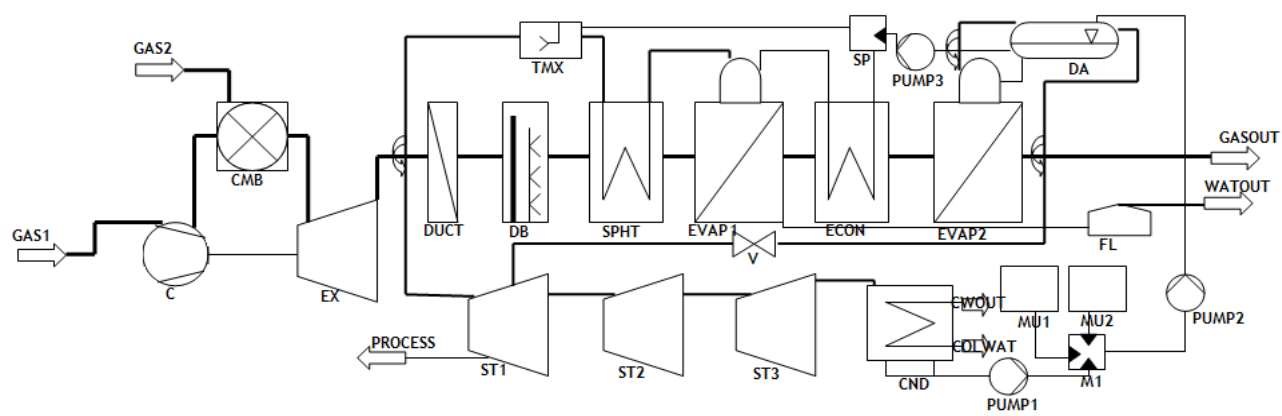

Fig. 2. Dual-Pressure combined cycle power plant.

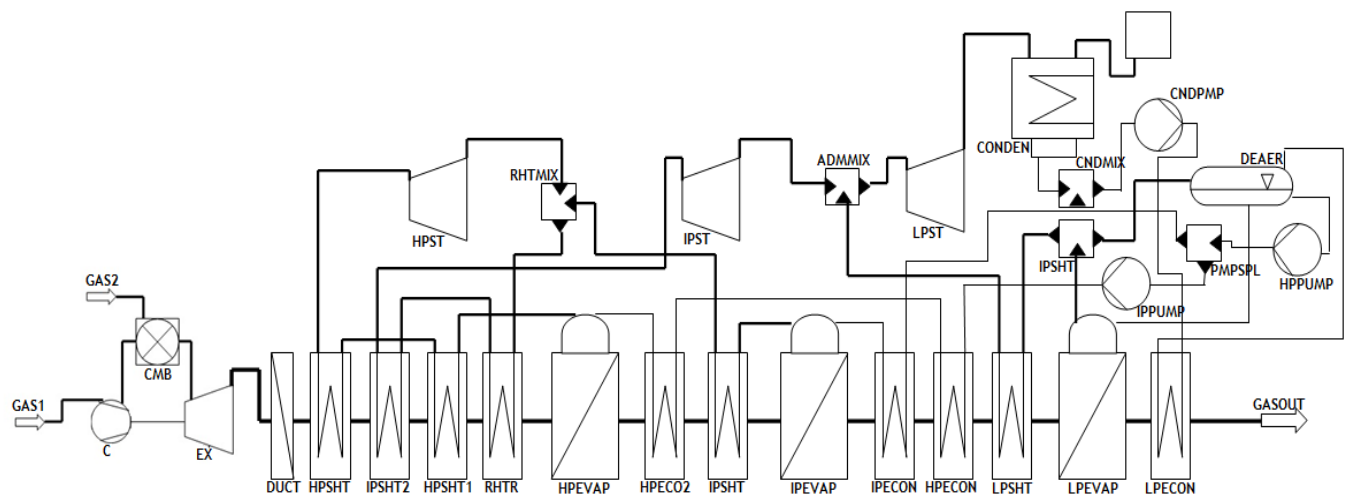

Fig. 3. Triple-Pressure reheat combined cycle power plant.

The analysis was carried out for ambient temperature $15^{\circ} \mathrm{C}$, pressure $101.353 \mathrm{kPa}$ and humidity 0.6. The aim of present work was to find optimum operative parameters of the whole combined cycle. The first studied parameter was pressure ratio. In computation, the pressure ratio was ranged from 6 to 30 with step equal to 1 for single-pressure and dual-pressure and from 6 to 45 for triple-pressure. The second studied parameter was temperature on the inlet to turbine in GT. The range of temperatures varied from 927 to $1227^{\circ} \mathrm{C}$ for single-pressure, from 927 to $1327^{\circ} \mathrm{C}$ for dual-pressure and from 1127 to $1427^{\circ} \mathrm{C}$ with a step equal $100^{\circ} \mathrm{C}$. Additionally, for single-pressure with supplementary firing CC temperature of SF was studied. Assumption of difference of $250^{\circ} \mathrm{C}$ between exhaust gas from turbine and temperature from SF was taken. Analyzed temperatures ranged from 527 to $927^{\circ} \mathrm{C}$.

The models for analyze were created in GateCycle ${ }^{\mathrm{TM}}$ software. Each system was built from built-in geometries which represents particular parts of PP connected in proper configuration. All elements' properties were fixed or based on software settings (Table 1). In this software two modes of design can be 
distinguished:

- Design (design phase) - selection of proper elements of the system and setting of physical parameters, standard values, ways of distribution of geometries and theirs interconnection.

- Off-design (simulation phase) - analysis of parameters' changes and optimization for fixed conditions.

Creation of model and its study is carried out according to the following stages:

- Scheme construction- geometries selection and their linkage

- Entering data for particular elements

- Error correction

- Simulation

- Results generation- efficiency, output, ambient conditions [16]

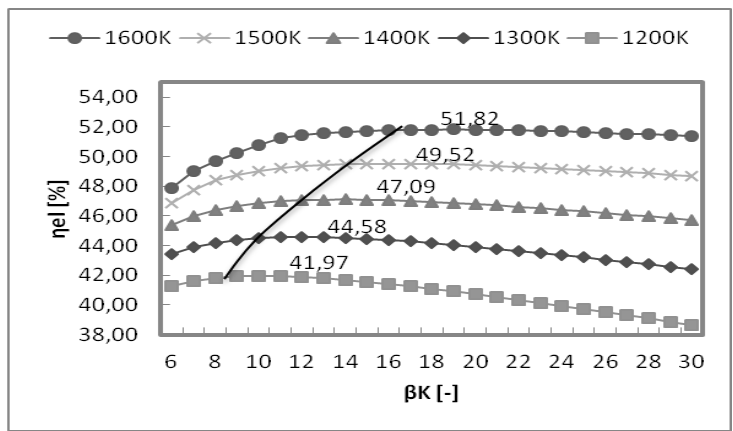

Fig. 4. Relation between electric power efficiency, pressure ratio and gas turbine inlet temperature of 1P.

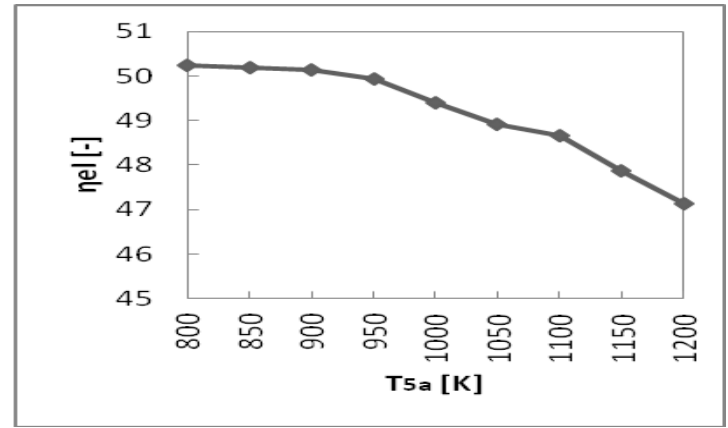

Fig. 5. Impact of supplementary firing on electric power efficiency of 1P.

\section{Results and Analysis}

The results obtained in simulation show big differences regarding efficiency, Net power and pressure ratio. Fig. 4 shows that by increasing temperature on the inlet to gas turbine, efficiency growth can be obtained. Also, efficiency depend on pressure ratio what is particularly significant in terms of low values. It means that the highest efficiency which can be achieved for temperature $1200 \mathrm{~K}$ is equal 9(efficiency $41.97 \%$ ) and for $1600 \mathrm{~K} 16$ (efficiency $51.82 \%$ ). Growth of gas turbine inlet temperature causes shallow in that characteristic what shows that optimal pressure ratio should be chosen from higher values.

To check how supplementary firing influences efficiency and Net electric power generation the analysis was carried out at with different duck burner temperatures. Fig. 5 shows that by increasing SF temperature efficiency of whole system decreases. Approximately by increasing that temperature by $1 \mathrm{~K}$ efficiency decreases by $0.00588 \%$ what makes huge differencies when that temperature is rised by bigger quantities. However, otherwise is with Nel which increases by $0.187 \mathrm{MW}$ at $1 \mathrm{~K}$ what is shown on Fig. 6 . That growth refers only to steam cycle as SF is located after GT but lower exergy use of burned fueal means lower efficiency.

The same scheme of results like in single-pressure $\mathrm{CC}$ were obtained in dual- and triple-pressure 
reheat CC. Fig. 7 and Fig. 8 demonstrate the optimal point for different temperatures on the inlet to gas turbine and what pressure ratio is the best to receive the highest efficiency.

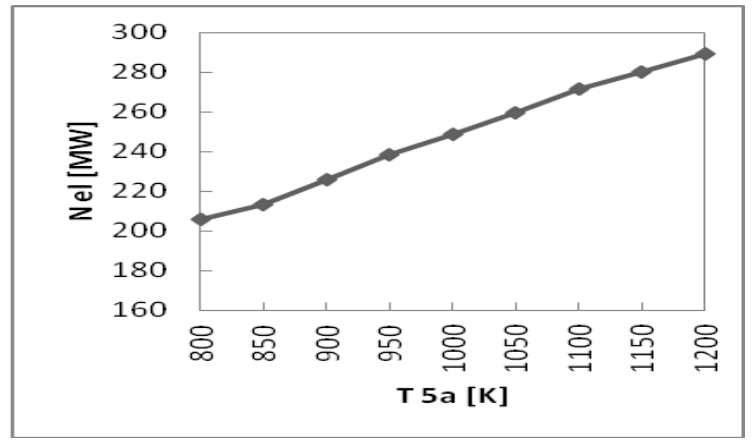

Fig. 6. Impact of supplementary firing on Net power of 1P.

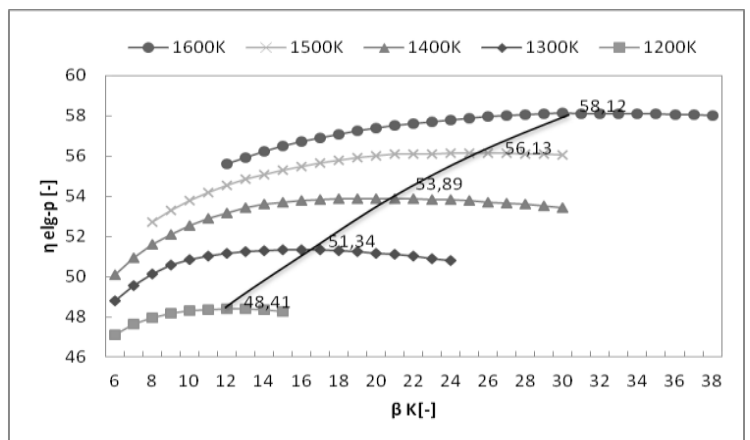

Fig. 7. Relation between electric power efficiency, pressure ratio and gas turbine inlet temperature of $2 \mathrm{P}$.

Table 2. Power of 1P, 2P, 3PR combined cycle power plant depending on temperature on the inlet to the gas turbine

\begin{tabular}{cccccccccc}
\hline & \multicolumn{3}{c}{ 3PR } & \multicolumn{9}{c}{ 2P } & \multicolumn{3}{c}{ 1P } \\
\hline & Nel & NelGT & NelST & Nel & NelGT & NelST & Nel & NelGT & NelST \\
\hline 1200 & - & - & - & 118,826 & 93,73484 & 25,09111 & 177,61 & 95,93 & 81,68 \\
1300 & - & - & - & 156,8967 & 119,4555 & 37,44117 & 200,98 & 118,92 & 82,06 \\
1400 & 202,0565 & 146,5412 & 55,51539 & 196,6639 & 145,6359 & 51,02797 & 224,72 & 142,28 & 82,44 \\
1500 & 245,0221 & 173,8087 & 71,21343 & 238,0867 & 172,2679 & 65,81883 & 248,87 & 166,04 & 82,83 \\
1600 & 288,3581 & 201,5482 & 86,80984 & 279,7214 & 199,3579 & 80,36346 & 273,42 & 190,19 & 83,23 \\
1700 & 310,2515 & 215,598 & 94,65345 & - & - & - & - & - & - \\
\hline
\end{tabular}

In the $2 \mathrm{P}$ combined cycle there is significant growth of efficiency by increasing inlet temperature to the gas turbine. From $48.41 \%$ for pressure ratio equal 12 it rises to $58.12 \%$ for pressure ratio equal 31 . Similarities can be observed in 3PR combined cycle where efficiency grows from 55.34 for $1400 \mathrm{~K}$ and pressure ratio 18 to $60.4 \%$ for $1700 \mathrm{~K}$ and pressure ratio equal 35 .

The analysis has shown that temperature on the inlet to the gas turbine is very important in optimizing work of whole combined cycle power plant. Fig. 9 demonstrate how it can influence all cycles studied in this paper. Previously mentioned ranges of temperature for every cycle point out visible difference between single-pressure and dual- and triple-pressure reheat combined cycles. It can be noticed that by increasing that temperature we can receive huge profits in efficiency( $10.65 \%$ for dual-pressure) as well as in power output what shows Table 1. In 3PR cycle temperature on the inlet to the gas turbine plays important role in increasing efficiency of whole system. With every $1 \mathrm{~K}$ efficiency increases by 0.02 
percentage points and with $300 \mathrm{~K}$ difference we rice efficiency by 5.54 percentage points (Fig. 9). The same is with power output (Table 1) which is increased by $0.43 \mathrm{MW}$ with every $1 \mathrm{~K}$. The proportion between power output from GT and ST decreases what is a one of the aims of combined cycles [2].

In current study the ambient conditions were established with temperature equal $15^{\circ} \mathrm{C}$, pressure $101.325 \mathrm{kPa}$ and humidity 0.6 . Because such conditions are not stable for working power plants and depend on position, atmospheric conditions and climatic zone the study was carried out with different ambient temperature ranged rom -20 to $30^{\circ} \mathrm{C}$ with a step equal $5^{\circ} \mathrm{C}$. Table 2 shows that the ambient temperature rise causes drop in power output. With $1 \mathrm{~K}$ growth power output decreases by $0.57 \mathrm{MW}$ for $1 \mathrm{P}$. Based on this analysis similar results to $1 \mathrm{P}$ can be noticed.

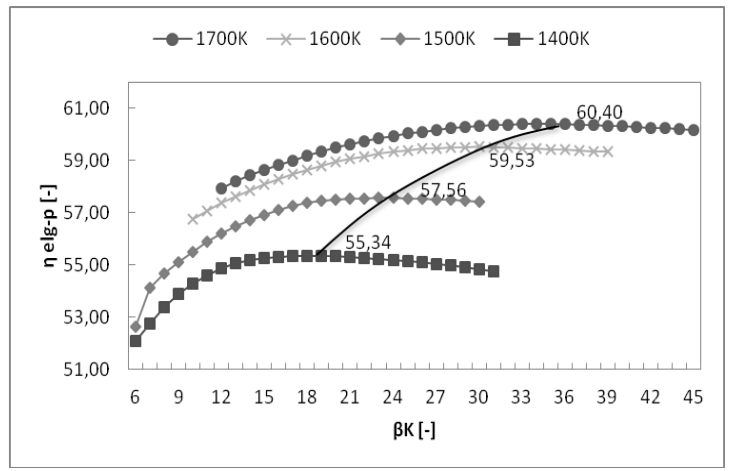

Fig. 8. Relation between electric power efficiency, pressure ratio and gas turbine inlet temperature of 3PR.

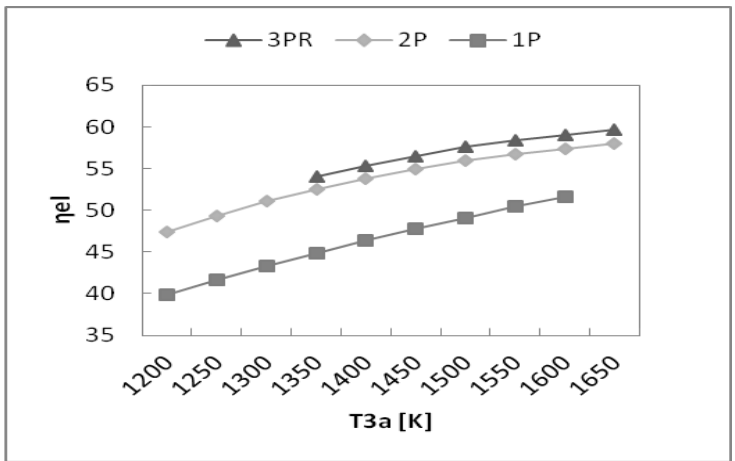

Fig. 9. Comparison of impacts of temperature on the inlet to gas turbine on three different cycles: $1 \mathrm{P}, 2 \mathrm{P}, 3$.

Table 3. Change in power output for 1P, 2P, 3PR combined cycle power plant depending on ambient temperature

\begin{tabular}{ccccccccccccc}
\hline & & 303,15 & 298,15 & 293,15 & 288,15 & 283,15 & 278,15 & 273,15 & 268,15 & 263,15 & 258,15 & 253,15 \\
\hline 3PR & Nel & 243,31 & 245,37 & 247,70 & 250,27 & 253,00 & 255,90 & 258,89 & 261,96 & 265,10 & 268,29 & 271,56 \\
& NelGT & 167,01 & 169,45 & 172,06 & 174,80 & 177,64 & 180,57 & 183,57 & 186,62 & 189,70 & 192,82 & 195,96 \\
& NelTG & 76,30 & 75,92 & 75,64 & 75,47 & 75,36 & 75,32 & 75,32 & 75,34 & 75,40 & 75,47 & 75,60 \\
& Nel & 228,30 & 230,51 & 232,99 & 235,69 & 238,56 & 241,57 & 244,70 & 247,90 & 251,16 & 254,47 & 257,81 \\
2P & NelGT & 163,64 & 166,19 & 168,91 & 171,76 & 174,72 & 177,76 & 180,88 & 184,04 & 187,24 & 190,48 & 193,74 \\
& \multirow{2}{*}{ NelTG } & 64,67 & 64,32 & 64,08 & 63,93 & 63,84 & 63,81 & 63,82 & 63,86 & 63,92 & 63,99 & 64,07 \\
& Nel & 240,45 & 242,63 & 245,04 & 247,66 & 250,42 & 253,32 & 256,32 & 259,39 & 262,52 & 265,69 & 268,89 \\
& \multirow{2}{*}{ NelGT } & 157,01 & 159,47 & 162,10 & 164,84 & 167,70 & 170,63 & 173,63 & 176,68 & 179,77 & 182,89 & 186,02 \\
& NelTG & 83,44 & 83,15 & 82,95 & 82,81 & 82,73 & 82,69 & 82,69 & 82,71 & 82,75 & 82,80 & 82,86 \\
\hline
\end{tabular}




\section{Conclusions}

In present study three different cycles were modeled: single-pressure with supplementary firing, dualpressure and triple-pressure reheat combined cycles. These analyses allow the following conclusions to be drawn:

- Based on the pressure ratio characteristic the optimal value for particular temperature can be chosen. Depending on the temperature value, optimal ratio is different and increases with growth of gas turbine inlet temperature. The most significant difference occurs in single-pressure with supplementary firing CC. In dual- and triple reheat cycles that difference is not very significant. For all of them characteristics are the shallowest around extreme point. Thanks to that specific pressure ratio can be chosen from wide spectrum of values.

- The gas turbine inlet temperature influences both efficiency and power output. Additionally, that parameter increases share of produced energy from steam part in total power output, because temperature on the inlet to HRSG increases.

- Supplementary firing causes efficiency loses however increases power output. As from thermodynamic point of view it is a loss of energy but it can be used when cauldron flexibility is needed.

- The last analyzed parameter was ambient temperature. The obtained results show that with ambient temperature growth efficiency and power output decreases.

In order to achieve the highest efficiencies dual- and triple-pressure combined cycles should be used. These two cycles have significantly higher efficiency than single-pressure combined cycle. It is important because every growth of efficiency gives additional gaining and significantly cut in greenhouse gases production.

As present study showed, gas and steam combined cycles are very complex systems what makes them very sensitive on different parameters. To achieve the highest efficiency and power output some of them studied in this paper should be fixed. However, it does not contain economic as well as material analyses which are important in developing new energy technologies, especially combined cycles.

\section{References}

[1] Wedzik A. (May 2006). Uklady kombinowane produkcji energi elektrycznej. [Online] Available: http://elektroenergetyka.pl/upload/file/2006/5/elektroenergetyka_nr_06_05_2.pdf

[2] Kotowicz J, Elektrownie Gazowo-Parowe, Kaprint, Lublin; 2008.

[3] Chase DL. Combined-cycle. Development, evolution and future, Technical report GER-4206, GE Power Systems, Schenectady, NY, 2000.

[4] Horlock JH. Combined power plants- past, present and future. ASME Journal Engineering for Gas Turbines Power, 1995; 117:608-616.

[5] Unger DH. Comparative Study on Energy R\&D Performance: Gas Turbine Case Study, Energy Laboratory. Massachusetts Institute of Technology, 1998.

[6] Bartnik R. Elektrownie i Elektrociepłownie Gazowo-Parowe. WNT, Warszawa; 2009.

[7] Polyzakis A, Koroneos C, Xydis G. Optimum gas turbine cycle for combined cycle power plant. Energy Conversion and Management, 2008; 49:551-563.

[8] Kotowicz J, Job M, Brzeczek M. The characteristics of ultramodern combined cycle power plants. Energy, 2015; 92:197-211.

[9] Franco A, Russo A. Combined cycle plant efficiency increase based on the optimization of the heat recovery steam generator operating parameters. International Journal of Thermal Sciences, 2002; 41:843-859.

[10] Kehlhofer R, Hannemann FS, Rukes B. Combined-Cycle Gas\&Steam Power Plants. Ed. Pennwell, USA; 2009.

[11] Ganjehkaviri A, Mohd Jaafar MN, Hosseini SE. Optimization and the effect of steam turbine outlet quality on the output power of combined cycle power plant. Energy Conversion and Management, 2015; 89:231-243.

[12] Rao AD, Francuz DJ, An evaluation of advanced combined cycles. Applied Energy, 2013; 102:1178-1186.

[13] Marrero IO, Lefsaker AM, Razani A, Kim KJ. Second law analysis and optimization of combined triple power cycle. Energy Conversion and Management, 2002; 43:557-573.

[14] Arrieta F, Lora E. Influence of ambient temperature on combined-cycle power-plant performance. Applied Energy, 2005; 80:261-272. 
[15] Godoy E, Scenna NJ, Benz SJ. Families of optimal thermodynamic solutions for combined cycle gas turbine(CCGT) power plants. Applied Thermal Engineering, 2010; 30:569-576.

[16] Augusiak A. GateCycle- Symulator obiegów energetycznych. [Online]. Available: http://www.ely.pg.gda.pl/ aandy/files/mue_sem6_energetyka/mue_sem6_en_w05.pdf 